$\begin{array}{ll}\text { Received } & : 10 \text { Agustus } 2020 \\ \text { Revised } & : \text { 13 Desember 2020 } \\ \text { Accepted } & : \text { 14 Desember 2020 } \\ \text { Online } & : 15 \text { Desember } 2020 \\ \text { Published } & : \text { : } 18 \text { Desember } 2020\end{array}$

\title{
Uji Kelayakan Tanah terhadap Penanaman Tanaman Pisang, Singkong, dan Ubi Jalar di Daerah Sekitar Villa Silma Kecamatan Cilember Kabupaten Bogor
}

\author{
Imam Safir Alwan Nurza ${ }^{1, a)}$, Proborini Indah Nursari ${ }^{1}$, Andhika Zakhyana ${ }^{1}$, Ali \\ Akbar ${ }^{1}$, Mutiara Suryadi ${ }^{1}$, Niken Purnamasari ${ }^{1}$, Fadla Maulida Khofifi ${ }^{1}$, \\ Muhammad Rizky Wafyan ${ }^{2}$, Rezti Wahyu Noviyanti ${ }^{2}$, Nico Andreas ${ }^{3}$, Felixs \\ Ginola $^{3}$, Kendai Mercelli ${ }^{3}$, Muhammad Agung Aprialdi ${ }^{4}$, Mela Faryhunnisa ${ }^{5}$, \\ Dinda Lestari Ma'wa ${ }^{6}$, Faradhia Aura Risma ${ }^{7}$
}

\author{
${ }^{1}$ Biologi, Fakultas Matematika dan Ilmu Pengetahuan Alam, Universitas Negeri Jakarta \\ ${ }^{2}$ Pendidikan Kimia, Fakultas Matematika dan Ilmu Pengetahuan Alam, Universitas Negeri Jakarta \\ ${ }^{3}$ Kimia, Fakuktas Matematika dan Ilmu Pengetahuan Alam, universitas Negeri Jakarta \\ ${ }^{4}$ Tata Boga, Fakultas Teknik, Universitas Negeri Jakarta \\ ${ }^{5}$ Psikologi, Fakultas Psikologi, Universitas Negeri Jakarta \\ ${ }^{6}$ Bimbingan dan Konseling, Fakultas Ilmu Pendidikan, Universitas Negeri Jakarta \\ ${ }^{7}$ Teknik Informatika dan Komputer, Fakultas Teknik, Universitas Negeri Jakarta
}

凶: ${ }^{\text {a) }}$ imamsafiralwannurza2017@gmail.com

\begin{abstract}
Cilember is an area that has great potential as a plantation area because it has a cool climate and has fairly good irrigation. Cilember Plantation has several types of plants, namely banana, cassava, and sweet potato. But the majority of plantations in the Cilember area are sweet potatoes. The plantations around Villa Silma in Cilember Subdistrict have several problems, namely the gravel, dry soil posture, banana leaf, and cassava leaves withered and environmental stress. The purpose of this research was to find out the feasibility of soil on banana, cassava, and sweet potato plants in the garden land around Villa Silma in Cilember District, Bogor Regency. The research method used was descriptive qualitative observational data collection techniques that include humidity, $\mathrm{pH}$, texture, and color in the soil. Data analysis was performed descriptively qualitative and observations on humidity, $\mathrm{pH}$, texture, and color in the soil. The research results obtained are the soil in Cilember has a smooth, dry texture and resembles a pebble with a brown color, $40 \%$ soil moisture, and a pH of 6.5. The research conclusion is the land in the garden area around Villa Silma, Cilember Subdistrict, Bogor Regency is suitable as a place for planting cassava and sweet potatoes only.
\end{abstract}

Keywords: Banana, Cassava, Cilember, Land Worthiness, Sweet Potatoes.

\begin{abstract}
Abstrak
Cilember merupakan daerah yang punya potensi besar sebagai daerah perkebunan karena memiliki iklim yang sejuk dan mempunyai irigasi yang cukup baik. Perkebunan Cilember memiliki beberapa jenis tanaman yaitu pisang, singkong, dan ubi jalar. Namun mayoritas perkebunan di daerah cilember adalah ubi jalar. Perkebunan di sekitar Villa Silma Kecamatan Cilember memiliki beberapa permasalahan, yaitu postur tanah yang berbentuk kerikil, kering, daun tanaman pisang dan singkong layu dan stres lingkungan. Tujuan penelitian ini untuk mengetahui kelayakan tanah pada tanaman pisang, singkong, dan ubi jalar di lahan kebun sekitar Villa Silma di Kecamatan Cilember Kabupaten Bogor. Metode penelitian yang digunakan adalah deskriptif kualitatif dengan teknik pengumpulan data secara observasi yang meliputi kelembapan, pH, tekstur, dan warna pada tanah. Analisis data dilakukan secara deskriptif kualitatif dan observasi pada kelembapan, $\mathrm{pH}$, tekstur, dan
\end{abstract}


warna pada tanah. Hasil penelitian ini adalah tanah di Cilember memiliki tekstur halus, kering dan menyerupai kerikil dengan warna coklat, kelembapan tanah 40\%, dan pH 6,5. Kesimpulan Penelitian ini adalah Tanah di kebun daerah sekitar Villa Silma Kecamatan Cilember Kabupaten Bogor layak dijadikan tempat pada penanaman tanaman singkong dan ubi saja.

Kata Kunci: Cilember, Kelayakan Tanah, Pisang, Singkong, Ubi Jalar.

\section{PENDAHULUAN}

Wilayah Kecamatan Cilember yang terletak di Kabupaten Bogor, Jawa Barat, Indonesia. Daerah ini mempunyai perkebunan dengan iklim yang sejuk dan irigasi yang cukup baik. Tanah pada penanaman tanaman dilakukan sesuai dengan SNI, seperti SNI pada tanaman pisang salah satunya, yaitu tanah yang gembur, kaya bahan organik (humus), dan berdrainase baik dengan $\mathrm{pH} 4,5-8,5$ (pH optimum sekitar 6,0) serta kadar air tanah minimal 60\% dari kapasitas lapang (Zulkarnain, 2017). Kemudian, perkebunan di sekitar Villa Silma Kecamatan Cilember memiliki tiga macam jenis tanaman, yaitu pisang, singkong, dan ubi jalar. Namun, mayoritas tanaman perkebunan di daerah Kecamatan Cilember adalah pisang dan singkong.

Berdasarkan survei yang telah dilakukan, perkebunan di sekitar Villa Silma Kecamatan Cilember memiliki beberapa permasalahan yang terjadi, yaitu postur tanah yang berbentuk kerikil, kering, daun pada tanaman pisang layu, dan stres lingkungan. Sehingga, perlu adanya uji kelayakan tanah pada perkebunan sekitar Villa Silma Kecamatan Cilember agar tanaman dapat tumbuh dengan baik dan menghasilkan panen yang berkualitas serta berkuantitas. Kelayakan tanah adalah kondisi atau keadaan dan kemampuan tanah untuk mendukung pertumbuhan tanaman dengan berbagai komponen yang ada didalamnya, seperti biologi, kimiawi, dan fisika (Sutanto, 2005; Risa et al., 2018; Sartohardi et al., 2014).

Tanah adalah lapisan permukaan bumi yang secara fisik memiliki fungsi sebagai tempat tumbuh dan berkembangnya perakaran serta penopang tegak tumbuhnya tanaman juga menyuplai kebutuhan air dan udara. Secara kimiawi, tanah berfungsi sebagai gudang dan penyuplai hara atau nutrisi (senyawa organik dan anorganik sederhana dan unsur-unsur esensial) dan secara biologi berfungsi sebagai habitat biota (organisme) yang berpartisipasi aktif dalam penyediaan hara tersebut dan zat-zat aditif (pemacu tumbuh, proteksi) bagi tanaman (Hanafiah, 2014; Sutanto, 2005; Sartohardi et al., 2014).

Tanah dalam proses pembentukannya dapat menimbulkan sifat-sifat yang berbeda, sifat-sifat tersebut dibedakan menjadi dua, yaitu: fisika dan kimia. Tanah secara fisika memiliki dua sifat, yaitu tekstur dan warna tanah. Tekstur adalah perbandingan relatif antara fraksi pasir, debu dan liat, yaitu partikel tanah yang diameter efektifnya $2 \mathrm{~mm}$. Di dalam analisis tekstur, fraksi bahan organik tidak diperhitungkan. Bahan organik terlebih dahulu didestruksi dengan hidrogen peroksida (H2O2) (Agus dan Yustika, 2015; Agus et al., 2015; Hardjowigeno, 2003; Tangketasik et al., 2012). Hal ini disebabkan karena tekstur tanah berhubungan erat dengan pergerakan air dan zat terlarut, udara, pergerakan panas, berat volume tanah, luas permukaan spesifik, dan kemudahan memadat (Hardjowigeno, 2003; Arifin, 2010; Suriadikusumah dan Pratama, 2010).

Warna tanah yang sering dijumpai adalah warna kuning, merah, coklat, putih, dan hitam serta warna-warna tanah di antara warna-warna tersebut. Hal ini karena warna tanah dipengaruhi oleh beberapa faktor yang terdapat dalam tanah tersebut. Penyebab perbedaan warna permukaan tanah umumnya dipengaruhi oleh perbedaan kandungan bahan organik. Semakin tinggi kandungan bahan organik, warna tanah akan semakin gelap (Coleman et al., 2004; Sutanto, 2005; Anwar et al., 2016; Robbani et al., 2016; Margolang et al., 2015).

Tanah secara kimia terbagi menjadi dua, yaitu kelembapan dan $\mathrm{pH}$ tanah. Kelembapan tanah adalah air yang mengisi sebagian atau seluruh pori-pori tanah atau jumlah air yang tersimpan di antara pori-pori tanah (Asdak, 2004; Karyati et al., 2018; Agus dan Yustika, 2015). Kelembapan tanah sangat dinamis, hal ini disebabkan oleh penguapan melalui permukaan tanah, transpirasi, dan perkolasi (Assolihat et al., 2019; Amaru et al., 2013; Karamina et al., 2017; Agus dan Yustika, 2015). 
Derajat keasaman tanah atau $\mathrm{pH}$ tanah adalah satuan derajat yang dipergunakan untuk menentukan tingkat keasaman atau kebasaan terhadap tanah. $\mathrm{pH}$ tanah sangat berpengaruh terhadap perkembangan dan pertumbuhan tanaman, baik secara langsung maupun tidak langsung. Pengaruh langsung berupa ion hidrogen, sedangkan pengaruh tidak langsung yaitu tersedianya unsur-unsur hara tertentu dan adanya unsur beracun. Kisaran $\mathrm{pH}$ tanah mineral biasanya antara 3,5-10 atau lebih. Sebaliknya untuk tanah gembur, $\mathrm{pH}$ tanah dapat kurang dari 3,0. Alkalis dapat menunjukkan $\mathrm{pH}$ lebih dari 3,6 (Hardjowigeno, 2010; Kamarina et al., 2017).

Penelitian ini dilakukan untuk mengetahui bahwa daerah sekitar Villa Silma Kecamatan Cilember dapat layak atau tidak dijadikan tempat penanaman pada tanaman pisang, singkong, dan ubi jalar melalui pengujiannya secara fisika meliputi tekstur dan warna, kimia dengan kelembapan dan $\mathrm{pH}$, dan biologi dengan adanya keberadaan cacing tanah.

\section{METODE}

Metode yang digunakan dalam penelitian ini adalah metode deskriptif kualitatif karena penelitian ini ingin mendeskripsikan fakta-fakta atau keadaan atau gejala yang terjadi di perkebunan sekitar Villa Silma Kecamatan Cilember. Kemudian, teknik pengumpulan data yang digunakan adalah observasi. Observasi yang akan dilakukan meliputi kelembapan, $\mathrm{pH}$, tekstur, dan warna pada tanah. Observasi yang dilakukan menggunakan instrumen luxmeter pada intensitas cahaya, altimeter pada ketinggian, soilmeter pada kelembapan dan $\mathrm{pH}$ tanah, thermometer pada suhu, dan ada atau tidaknya organisme cacing tanah.

Analisis data yang digunakan dalam metode penelitian ini adalah analisis deskriptif kualitatif yang bertujuan untuk memberikan deskripsi mengenai objek penelitian dan analisis observasi yang bertujuan untuk menggambarkan segala sesuatu yang berhubungan dengan objek yang diamati.

\section{HASIL DAN PEMBAHASAN}

Berdasarkan observasi yang telah dilakukan pada kelayakan tanah di daerah sekitar Villa Silma Kecamatan Cilember Kabupaten Bogor menunjukkan bahwa tanah berwarna coklat dengan tekstur halus, kering, dan bentuknya padat menyerupai kerikil, kelembapan tanah 40\%, pH didapatkan 6,5, dan tidak ditemukan cacing tanah yang dapat dilihat pada Tabel 1 .

TABEL 1. Kelayakan tanah pada penanaman tanaman kebun di daerah Cilember

\begin{tabular}{ccc}
\hline No & Parameter Observasi & Keterangan \\
\hline 1 & Tekstur & Halus, kering, dan padat menyerupai kerikil \\
2 & Warna & Coklat \\
3 & Kelembapan tanah & $40 \%$ \\
4 & $\mathrm{pH}$ & 6,5 \\
5 & Cacing Tanah & Tidak ditemukan \\
\hline
\end{tabular}

Kelembapan tanah menyatakan jumlah air yang tersimpan di antara pori pori tanah yang terus berubah, hal ini di sebabkan oleh penguapan melalui permukaan tanah. Kondisi kelembaban tanah sangat mempengaruhi kondisi tanaman, tingkat kelembapan tanah yang tinggi dapat menimbulkan permasalahan dan keadaan tanah yang terlalu lembap dapat mengakibatkan kesulitan dalam kegiatan permanen hasil pertanian (Lutfiyana et al., 2017; Zulkarnain, 2017; Karyati et al., 2018).

Kelembapan pada tanah kebun di derah sekitar Villa Silma mempunyai kelembapan 40\% yang dapat digolongkan sebagai kategori rendah, hal ini karena adanya kandungan air di dalam tanah kadarnya rendah (Raka et al., 2011; Lutfiyana et al., 2017). Pengaruh yang disebabkan pada kelembapan tanah ini adalah pada daun tanaman pisang terlihat layu (Nashar, 2015; Raka et al., 2011). Menurut Zulkarnain (2017) menyatakan bahwa tanaman pisang memerlukan kadar air tanah minimal $60 \%$, karenanya tanaman ini memerlukan suplai air secara intensif pada musim kemarau. Sedangkan pada tanaman singkong dan ubi jalar tidak terlihat adanya layu pada tanaman tersebut ini 
menandakan bahwa tanaman tersebut tahan terhadap kondisi kelembapan rendah pada tanah di kebun daerah sekitar Villa Silma.

Pada $\mathrm{pH}$ tanah sangat berpengaruh terhadap perkembangan dan pertumbuhan tanaman, faktorfaktor yang memengaruhi $\mathrm{pH}$ tanah adalah unsur-unsur yang terkandung dalam tanah, kandungan air, dan kisaran pH tanah yang bermineral biasanya antara 3,5-10 (Kamarina et al., 2017; Sutanto, 2005; Hardjowigeno, 2010). Hasil observasi menunjukkan bahwa $\mathrm{pH}$ tanah pada kebun di sekitar Villa Silma adalah 6,5. Menurut Sundari et al. (2014), pada umumnya unsur hara mudah diserap oleh akar tanaman pada $\mathrm{pH}$ tanah netral 6-7, karena pada $\mathrm{pH}$ tersebut sebagian besar unsur hara mudah larut dalam air. Pada tanaman ubi jalar dapat tumbuh dengan baik pada $\mathrm{pH}$ tanah yang sesuai berkisar antara 4,5-8.

Oleh karena itu, tanaman ubi jalar masih dapat tumbuh menjadi tanaman yang baik untuk ditanam pada kebun di sekitar Villa Silma. Tanaman pisang memiliki pH optimum sekitar 4,5 - 8,5 (Hardjowigeno, 2010; Sundari et al., 2014). Hal ini menyebabkan tanaman pisang dapat tumbuh dengan kondisi pH pada tanah kebun di sekitar Villa Silma. Derajat keasaman tanah atau $\mathrm{pH}$ tanah yang sesuai untuk budidaya singkong berkisar antara 4,5-8,0 (Sundari et al., 2014; Prabowo dan Subantoro, 2018; Coleman et al., 2004). Tanaman ini juga dapat hidup dengan baik pada kondisi pH tanah kebun di sekitar Villa Silma.

Observasi tekstur tanah di kebun pada daerah sekitar Villa Silma adalah halus, kering, dan menyerupai kerikil. Berdasarkan data sekunder klarifikasi tekstur tanah yang paling umum digunakan dalam pertanian adalah sistem klarifikasi menurut USDA materi yang lebih besar dari diameter 7,5 $\mathrm{cm}$ disebut sebagai batu, anatara 7,5 $\mathrm{cm}$ dan $2 \mathrm{~mm}$ disebut kerikil sedangkan materi yang ukurannya di bawah $2 \mathrm{~mm}$ didefinisikan sebagai materi yang tersusun dari pasir, lumpur, dan tanah liat yang terurai (LPT, 2006; Agus et al., 2015; Arifin, 2010; Suriadikusumah dan Pratama, 2010; Hardjowigeno, 2003).

Tanah pada penanaman singkong menunjukkan kering dan pecah-pecah yang menyebabkan ubi jalar terkena stres lingkungan. Namun, bila ditanam pada tanah yang mudah becek atau berdrainase jelek, dapat menyebabkan pertumbuhan tanaman ubi jalar kerdil, ubi mudah busuk, kadar serat tinggi, dan bentuk ubi berbenjol-benjol (Eulenstein et al., 2017; Suryani, 2016). Pada tekstur tanah di kebun sekitar Villa Silma ubi jalar masih dapat beradaptasi, karena tanahnya tidak terlalu basah dan tidak terlalu kering.

Tanah yang paling sesuai untuk singkong dan pisang adalah tanah yang berstruktur remah, gembur, tidak terlalu liat dan tidak terlalu poros serta kaya bahan organik (Zulkarnain, 2017; Nashar, 2015). Karena tekstur tanah pada kebun sekitar Villa Silma halus dan ditemukan keberadaan cacing tanah sehingga dapat mengindikasikan bahwa tanah pada kebun sekitar Villa Silma gembur atau tidak terlalu liat. Maka dari itu, singkong dapat tumbuh dengan baik di kebun sekitar Villa Silma.

Warna tanah sebagai indikator kesuburan tanah secara umum makin gelap tanah berarti makin tinggi produktivitasnya, secara berurutan mulai dari putih, kuning, kelabu, merah, coklat-kekelabuan, coklat-kemerahan, coklat, dan hitam (Hanafiah, 2014; Coleman et al., 2004; Anwar et al., 2016; Robbani et al., 2016; Margolang et al., 2015). Pada tanah kebun di sekitar Villa Silma berwarna coklat. Semakin berwarna gelap, maka makin tinggi kandungan bahan organik tanah tersebut. Warna tanah menjadi lebih terang dikarenakan intensitas pelindihan (pencucian dari horizon bagian atas ke horizon bagian bawah dalam tanah) dari ion-ion hara pada tanah tersebut (Hanafiah, 2014; Sutanto, 2005). Pada kebun di sekitar Villa Silma warna tanahnya berwarna coklat, maka tanah ini mengandung bahan organik yang cukup banyak.

Kemudian, tidak ditemukan cacing tanah di daerah sekitar Villa Silma Kecamatan Cilember yang merupakan organisme penyubur tanah yang berperan melakukan penguraian bahan organik untuk meningkatkan penyediaan hara di dalam tanah. Walaupun tidak ditemukan cacing tanah, tanaman singkong dan ubi jalar dapat tumbuh dengan baik karena di akar tanaman tersebut terdapat bintilbintil akar yang mengandung bakteri Rhizobium leguminosarum (Aziz, 2015; Zulfadli et al., 2012; Anwar dan Ginting, 2013; Widyati, 2013). 


\section{KESIMPULAN}

Tanah di kebun daer

ah sekitar Villa Silma Kecamatan Cilember Kabupaten Bogor layak dijadikan tempat pada penanaman tanaman singkong dan ubi saja karena tanaman tersebut dapat tumbuh pada tanah yang kering, halus, dan bentuknya menyerupai kerikil, warna tanah coklat, kelembapan 40\%, dan $\mathrm{pH} 6,5$. Namun, tidak layak dijadikan tempat penanaman pada tanaman pisang karena kandungan air yang terdapat di dalam tanah tersebut tidak tercukupi. Sehingga, tanaman menjadi stres dan layu.

\section{REFERENSI}

Agus, et al. (2015). Sifat Fisik Tanah dan Metode Analisisnya. Bogor: Balai Besar Litbang Sumberdaya Lahan Pertanian.

Agus F, Husnain, Yustika RD. (2015). Improving agricultural resilience to climate change through soil management. J. Litbang Pertan. 34 (4): 147-158.

Amaru, Kharistya, Suryadi, Edy, Bafdal, Nurpilihan, Asih, Fitri Punden. (2013). Kajian Kelembaban Tanah dan Kebutuhan Air Beberapa Varietas Hibrida DR UNPAD. Jurnal Keteknikan Pertanian. 1 (1): 107-115.

Anwar, E. K., Ginting, R. C. (2013). Mengenal Fauna Tanah dan Cara Identifikasinya. Jakarta: IAARD Press.

Anwar, Syaiful, Tjahyandari, Dyah, Idris, Komaruddin. (2016). Dasar-Dasar Ilmu Tanah. Tangerang Selatan: Universitas Terbuka.

Arifin, Moch. (2010). Kajian Sifat Fisik Tanah Dan Berbagai Penggunaan Lahan Dalam Hubungannya Dengan Pendugaan Erosi Tanah. Jurnal Pertanian MAPETA. 12 (2): 72-115.

Asdak, C. (2004). Hidrologi dan Pengelolaan Daerah Aliran Sungai. Yogyakarta: Universitas Gadjah Mada Press.

Assolihat, Nurul Kamila, Karyati, Syafrudin, Muhammad. (2019). Suhu dan Kelembaban Tanah pada Tiga Penggunaan Lahan di Kota Samarinda, Provinsi Kalimantan Timur. J. Hut. Trop. 3 (1): 4149.

Aziz, Abdul., A., M. (2015). Budidaya Cacing Tanah Unggul Alam Cacing. Jakarta: PT. Agro Media Pustaka.

Coleman, D. C., Crossley, D. A. Jr., Hendrix, P. F., (2004). Foundamental of Soil Ecology;Second Edition. USA: Elseveir Academic Press.

Eulenstein, F., Tauschke, M., Behrendt, A., Monk, J., Schindler, U., Lana, M. A. dan Monk,S. (2017). The Application of Mycottiza Fungi and Organic Fertilisers in Horticultural Potting Soil to Improve Water Use Efficiency of Crops. Horticulturae. 3 (1): 1-8.

Hardjowigeno, S. (2003). Ilmu Tanah. Jakarta: Akademika Pressindo.

Hardjowigeno, S. (2010). Ilmu Tanah. Jakarta: Akademika Pressindo.

Hanafiah, K.A. (2014). Dasar-dasar Ilmu Tanah. Jakarta: Rajawali Pers.

Nashar, H. (2015). Prospek Jenis Tanaman Pisang untuk Dilakukan Oleh Kelompok Usaha Tani. Iqtishadia. 2 (1): 91-116.

Karamina, H., Fikrinda, W., Murti, A.T. (2017). Kompleksitas Pengaruh Temperatur dan Kelembaban Tanah terhadap Nilai pH Tanah di Perkebunan Jambu Biji Varietas Kristal (Psidium guajava L.) Bumiaji, Kota Batu. Jurnal Kultivasi. 16 (3): 430-434.

Karyati, Putri RO, Syafrudin M. (2018). Suhu dan Kelembaban Tanah pada Lahan Revegetasi Pasca Tambang di PT Adimitra Baratama Nusantara, Provinsi Kalimantan Timur. Agrifor XII(1).

Lembaga Penelitian Tanah (LPT). (2006). Sifat Fisik Tanah dan Metode Analisisnya. Bogor: Lembaga Penelitian Tanah.

Lutfiyana, et al. (2017). Rancang Bangun Alat Ukur Suhu Tanah, Kelembaban Tanah, dan Resistansi. Jurnal Teknik Elektro.. 9 (2): 80-86.

Margolang, Rizky Dharmawan, Jamilah, Sembiring, Mariani. (2015). Karakteristik Beberapa Sifat Fisik, Kimia, dan Biologi Tanah pada Sistem Pertanian Organik. Jurnal Oline Agrotekoteaknologi. 3 (2): 717-723. 
Prabowo, Rossi, Subantoro, Renan. (2018). Analisis Tnah sebagai Indikator Tingkat Kesuburan Lahan Budidaya Pertanian di Kota Semarang. Jurnal Ilmiah Cendekia Eksakta. 2 (2): 59-64

Raka, I Dewa Nyoman, Wiswata, I.G.N. Alit, Budiasa, I Made. (2011). Pelestarian Tanaman Bambu sebagai Upaya Rehabilitasi Lahan dan Konservasi Tanah di Daerah Sekitar Mata Air pada Lahan Marginal di Bali Timur. Agrimeta. 1 (1): 1-11.

Risa, Hanna, Marsudi, Edy, Azhar. (2018). Analisis Kelayakan Usaha Perkebunan Kurma (Studi Kasus Kebun Kurma Barbate Kabupaten Aceh Besar). Jurnal Ilmiah Mahasiswa Pertanian Unsyiah. 3 (4): 550- 562.

Robbani, Ihwanudien Hasan, Trisnawati, Enny, Noviyanti, Rakhmadina, Rivaldi, Afrizal, Cahyani, Fadhilla Puji, Utaminingrum, Fitri. (2016). Aplikasi Mobile Scotect: Aplikasi Deteksi Warna Tanah dengan Teknologi Citra Digital pada Android. Jurnal Teknologi Informasi dan Ilmu Komputer. 3 (1): 19-26.

Sartohadi, J., Sianturi, R. S., Rahmadana, A. D. W., Maritimo, F., Wacano, D., Munawaroh, Suryani, T., Pratiwi, E. S. (2014). Bentang Sumberdaya Lahan Kawasan Gunungapi Ijen dan Sekitarnya. Yogyakarta: Pustaka Pelajar.

Sundari, Irma, Maruf, Widodo Farid, Dewi, Eko Nurcahya. (2014). Pengaruh Penggunaan Bioaktivitator EM4 dan Penambahan Tepung Ikan terhadap Spesifikasi Pupuk Organik Cair Rumut Laut Gracilaria sp. Jurnal Pengolahan dan Bioteknologi Hsil Perikanan. 3 (3): 88-94.

Suriadikusumah, Abraham, Pratama, Aryupti. (2010). Penetapan Kelembaban, Tekstur Tanah, dan Kesesuain Lahan untuk Tanaman Kina (Chinchona spp.) di Sub Das Cikapundung Hulu Melalui Citra Satelit Landsat-TM Image. Jurnal Agrikultur. 21 (1) 85-92.

Suryani, R. (2016). Otlook Komoditas Pertanian Tanaman Pangan: Ubi Jalar. Jakarta: Pusat Data dan Sistem Informasi Pertanian Kementrian Pertanian.

Sutanto, R. (2005). Dasar-Dasar Ilmu Tanah: Konsep Dan Kenyataan. Yogyakarta: Kanisius.

Tangketasik , Agustina, Wikarniti, Ni Made, Soniari, Ni Nengah, Narka, I Wayan. (2012). Kadar Bahan Organik Tanah pada Tanah Sawah dan Tegalan di Bali serta Hubungannya dengan Tekstur Tanah. AGROTROP. 2 (2): 101-107.

Widyati, E. (2013). Pentingnya Keragaman Fungsional Organisme Tanah terhadap Produktivitas Lahan. Tekno Hutan Tanaman. 6 (1): 29-37.

Zulfadli, Muyassir, Fikrinda. (2012). The Effect of Earth Worm and Organic Matter Application on Properties of Soil Compaction. Jurnal Manajemen Sumberdaya Lahan. 1 (1): 54-61.

Zulkarnain. (2017). Budidaya Buah-Buahan Tropis. Yogyakarta: Deepublish. 